\title{
Association between dental fear and eating disorders and Body Mass Index among Finnish university students: a national survey
}

Mohammad Jalil Sharifian ${ }^{1,2}$, Vesa Pohjola ${ }^{1,3}$, Kristina Kunttu $^{4}\left(\mathbb{0}\right.$ and Jorma I. Virtanen ${ }^{2,5^{*}}$ (D)

\begin{abstract}
Background: Little is known about the association between eating disorders (ED) and dental fear. This study investigated the association between dental fear and EDs through body mass index (BMI), and SCOFF (sick, control, one stone, fat, food) questionnaire among Finnish university students. We hypothesised that dental fear is associated with EDs and BMI.

Methods: We used the latest data from the Finnish University Student Health Survey 2016. This survey targeted undergraduate Finnish students $(n=10,000)$ of academic universities and universities of applied sciences. We enquired about e.g. age, gender, height, weight, educational sector and perceived mental well-being. We used the SCOFF questionnaire to assess those at risk for developing EDs. The question 'Do you feel scared about dental care?' enquired about dental fear. We used the chi-square test and gender-specific logistic regression to analyse the associations between dental fear, EDs and BMI controlling for age, educational sector and mental well-being.

Results: In total, 3110 students participated in the study. Overall $7.2 \%$ of the students reported high dental fear and 9.2\% scored SCOFF positive; more women than men reported high dental fear $(11.2 \%$ vs. $3.8 \%, p<0.001)$ and scored positive on SCOFF (14.2\% vs. 3.6\%, $\mathrm{p}<0.001)$. Gender modified the association between dental fear and EDs and BMI. Among females, when controlling for educational sector and BMI, those with positive SCOFF score were more likely to have high dental fear than those with negative SCOFF score (OR=1.6; $\mathrm{Cl}=1.0-2.4)$. After adding perceived mental well-being to the gender-specific regression analyses, overweight and obese males, $\mathrm{BMI} \geq 25(\mathrm{OR}=2.4 ; \mathrm{Cl} 1.3-4.4)$ and females with poor to moderate mental well-being $(\mathrm{OR}=2.1 ; \mathrm{Cl} 1.4-2.9)$ were more likely than their counterparts to have high dental fear.
\end{abstract}

Conclusions: Among the Finnish university students BMI in males and problems of mental well-being in females were positively associated with high dental fear. The results of this study support possible common vulnerability factors that dental fear and other psychological disorders may share.

Keywords: Dental fear, Eating disorders, SCOFF, BMI, Students

*Correspondence: jorma.virtanen@uib.no

2 Department of Clinical Dentistry, University of Bergen, Bergen, Norway

Full list of author information is available at the end of the article

\begin{abstract}
Background
High dental fear with irregular dental attendance has long been a widespread dental health topic worldwide. Studies have reported that $12 \%$ to $29 \%$ of children and adolescents experience dental fear/anxiety [1] and that up to $37 \%$ of the adult population suffer from moderate or very high dental fear [2]. Despite advancements in new
\end{abstract}

(c) The Author(s) 2021. Open Access This article is licensed under a Creative Commons Attribution 4.0 International License, which permits use, sharing, adaptation, distribution and reproduction in any medium or format, as long as you give appropriate credit to the original author(s) and the source, provide a link to the Creative Commons licence, and indicate if changes were made. The images or other third party material in this article are included in the article's Creative Commons licence, unless indicated otherwise in a credit line to the material. If material is not included in the article's Creative Commons licence and your intended use is not permitted by statutory regulation or exceeds the permitted use, you will need to obtain permission directly from the copyright holder. To view a copy of this licence, visit http://creativecommons.org/licenses/by/4.0/. The Creative Commons Public Domain Dedication waiver (http://creativeco mmons.org/publicdomain/zero/1.0/) applies to the data made available in this article, unless otherwise stated in a credit line to the data. 
technologies in dentistry which have made treatment visits shorter and more comfortable, new studies report minor positive changes. Longitudinal studies have also shown that high dental fear persists regardless of age, gender or education level $[3,4]$.

Eating disorders (ED) are "mental disorders defined by abnormal eating habits that negatively affect a person's physical or mental health" [5], of which Anorexia nervosa (AN), Bulimia nervosa (BN), and atypical EDs are the three main types. Eating disorders often occur together with other mental disorders. A study in Finland found that more than two thirds of ED patients presented with at least one other mental disorder [6]. Other studies have found that EDs and dental fear are associated with vulnerability to psychopathology $[6,7]$, suggesting that EDs and dental fear may share common underlying vulnerability factors. The cognitive vulnerability model provides ways of understanding the factors that contribute to the onset and maintenance of psychological problems [8].

Patients with high dental fear are more likely to present with psychological problems such as anxiety disorders, mood disorders, emotional dysregulation, alcohol dependence and regular tobacco use [9-11]. The same underlying factors are also prominent in people with eating disorders $[12,13]$. Moreover, studies report higher levels of dental fear in EDs patients than in the general population $[14,15]$.

Like high dental fear, EDs are noticeably more prevalent among young women than among men [16]. In Finland, EDs reportedly occur in as many as $24 \%$ of adolescent girls [17] with the risk for bulimia nervosa peaking in the 16-20 years age group [18]. The late teens and early adulthood are considered a critical period for establishing habits and beliefs [19]. This transitional period of experimentation towards an independent lifestyle could affect their health behaviours, namely their eating habits [20]. Thus, using simple and valid screening tools such as SCOFF-questionnaire (Sick, Control, One stone, Fat, Food) is crucial for the early identification of potential patients developing EDs [21].

Concerns about body shape and weight play important roles in the development of EDs, which are evident in the close association of EDs with body mass index (BMI) [22]. Researchers often use this measure of weight to identify patterns of EDs [23, 24]. Few studies have investigated the association between dental fear and weight (BMI), and the results are inconsistent $[25,26]$.

Patients with high dental fear or ED present with major dental health issues [11]. However, studies reporting an association between dental fear and EDs are scarce. This study aimed to evaluate the associations between dental fear and EDs (SCOFF status) and BMI, while controlling for age, gender, educational sector, attitude to food, and mental well-being among a representative sample of Finnish university students. We hypothesised that high dental fear is associated with EDs and BMI; those with risk for EDs or abnormal $\mathrm{BMI}$ are more prone to high dental fear compared to those without risk for EDs or normal BMI.

\section{Methods}

\section{Study design and settings}

The present cross-sectional study used the data from a national survey conducted every four years by the Finnish Student Health Service (FSHS) known as the national University Student Health Survey (USHS). The USHS aims to investigate students' physical, mental and social health, key aspects of health-related behaviour, as well as the use of health services and opinions concerning the quality of the services [27]. In addition, the national survey explores a range of factors related to health, health behaviours and study ability, such as social relationships, studying and subsistence. The USHS 2016 report includes the complete questionnaire. It comprises several validated questionnaires as subsets and other self-standing items [27]. The questionnaire was in Finnish and Swedish (official languages in Finland). Participation in the survey is totally voluntary. We collected the data used here anonymously from the most recent survey carried out in 2016 with the permission of the FSHS authorities and the Ethics Committee of the University of Turku [27].

\section{Participants}

The target population comprised Finnish undergraduate students under 35 years studying in Finnish universities, namely academic universities (Univ) and universities of applied sciences (UAS). This study included 14 out of 15 Univ and 24 out of 26 UAS, inclusion and exclusion criteria for the study and handling of the missing data are described in detail in the USHS report [27]. The study population comprised of 10000 students (Univ: 4996, UAS: 5004) who received an initial invitation followed by five reminders (all were sent by email, except for the third, which was sent by mail). FSHS anonymised the participants by deleting personal data and adding ID numbers before the researchers had access to it. No incentives for answering were used. Participants with unspecified gender were excluded from the study. Statistical procedures (including post-stratification) were used to count weights for men and women separately for the educational sectors [27]. After weighting adjustments, the sample comprised $47 \%$ men and $53 \%$ women, representing well the target population. 


\section{Dependent variable}

The question "Do you feel scared about dental care?" enquired about the outcome variable of the study, dental fear with three answer options: "Not at all", "Somewhat" and "Very". We considered high dental fear to have the most critical impacts on dental health, failure to seek dental care and early termination of treatment plans. We therefore combined the two former answers options ("Not at all" and "Somewhat") as the reference group for the data analyses. The question used refers directly to 'dental care' and can be considered as a measure of dental fear [28]. Previous studies in the Nordic countries have confirmed the validity and reliability of assessing dental fear with a single question [29-31].

\section{Independent variables}

The questionnaire (Additional file 1) included SCOFF, the most widely used screening test for eating disorders [32]. It consists of five short questions on the main aspects of EDs (i.e. self-induced vomiting, losing control on amounts of servings, prominent recent weight loss, the perception of being fat and whether food dominates the respondent's life). The questions were presented in the original order in closed Yes/No format; we considered two or more "Yes" answers a positive result (SCOFF positive), suggesting a high probability of having an ED [21]. A very recent systematic review and meta-analysis of 25 validation studies of SCOFF, reported a pooled sensitivity and specificity of $86 \%$ and $83 \%$, respectively [32]. Validations of the Finnish version of SCOFF have found $78 \%$ sensitivity and $87 \%$ specificity, suggesting its usefulness in high-risk populations, such as adolescents and university students [33].

We used the self-reported height and weight to calculate BMI (weight $(\mathrm{Kg})$ divided by the square of height (m2)). We considered BMI of $<15$ or $>50$ as exclusion criteria, but after examining the BMI scores, no such outliers were found. We classified the results as underweight $(\mathrm{BMI}<18.5)$, normal weight (BMI 18.5-24.9), overweight (BMI 25-29.9) and obese and extremely obese $(\mathrm{BMI} \geq 30)$. Self-reported height and weight has been shown to be a reliable measure of BMI [34-36].

We assessed the participants' perceived state of mental well-being with the question "How would you describe your current state of mental well-being (e.g. mental balance)?" with the answer options "Very poor", "Poor", "Moderate", "Good" and "Very good" (see Appendix). We later grouped these answer options into two categories: "Poor or moderate" which included the options "Very poor", "Poor", "Moderate") and "Good or Very good" (which included the options "Good" and "Very good"). [31] This question about mental well-being was first used in the USHS 2012. Since the question directly refers to "mental balance", it can be considered as a measure of perceived mental well-being [28].

We categorized age into three groups: 19-24, 25-30 and $31-35$ years. This was done because age groups are different. The youngest age group e.g. has entered the Univ or UAS directly of shortly after graduating from college and they have shorter time from the onset of possible EDs.

In the questionnaire, a single question enquired about attitude towards food ("Is your attitude towards food normal?") with three answer options: "Yes", "No" and "I don't know". We interpreted the last option as avoiding answering and combined the latter two options in the analysis to make "normal attitude towards food" as the reference group. This question was included in this study as a general indicator of attitude towards food and was not use in the logistic regression analyses. (Students with not normal attitude towards food were more likely to report high dental fear in our previous study [11].)

The question "Has a doctor or psychologist diagnosed any permanent, long-term or frequently recurring illness, health problem or trauma that has caused you symptoms, or required treatment over the past 12 months (e.g. Anorexia, Bulimia or other EDs)?" assessed diagnosed EDs; the answer options were "Yes" or "No".

\section{Statistical analyses}

We used cross-tabulations to assess bivariate associations between dental fear and, BMI, SCOFF status, attitude towards food, diagnosed eating disorders (during last 12 months), age, gender and educational sector (Univ or UAS). The chi-squared test served to evaluate the statistical differences of the bivariate associations. After checking collinearity, we performed logistic regression analyses to test our hypotheses. Dental fear was the dependent variable and BMI, SCOFF status, age and educational sector were covariates. (Due to the low number of ED diagnosis this variable was not included in the logistic regression analyses.) We entered perceived mental well-being into the final model along with all other covariates to eliminate any possible confounding effect. We performed modelling separately, but with the same approach, for both genders. We considered values of $\mathrm{p}<0.05$ statistically significant. Weighting adjustments in the analyses served to correct for the underrepresentation of men in the data [27]. We used IBM SPSS Statistics for Windows, Version 25 for all analyses.

\section{Results}

A total of 3110 students participated in this study. Participation was higher among women than among men (39\% and 22\%, respectively) and to correct this weighting 
adjustments were used. In twenty cases the respondents had not specified their gender as male or female and they were excluded from the study. The overall response rate was $31 \%(n=3090$, Univ $39 \%$, UAS $25 \%)$.

Table 1 shows the participants' background factors and distribution by gender of the variables studied. Most of the participants $(91.1 \%)$ belonged to $19-30$ years age group, and more than half (59.4\%) attended academic universities. About one fifth of students reported abnormal attitude towards food ('No' and 'I don't know' alternatives comprised $8.1 \%$ and $11.2 \%$ of the responses, respectively). Females reported abnormal attitude to food more often than did males $(26.4 \%$ vs. $11.4 \%, \mathrm{p}<0.001)$. Overall, $9.2 \%$ of the students scored positive on SCOFF.
More females than males had a positive SCOFF status $(\geq 2)$, but not normal weight was reported more often in males than in females (both $\mathrm{p}<0.001$ ). High dental fear was more often reported in females than in males $(11.2 \%$ vs. $3.8 \%, \mathrm{p}<0.001)$, accounting for $7.8 \%$ of all participants. Altogether 39 students reported a diagnosed eating disorder over the past 12 months and $53.8 \%$ of them scored positive in the SCOFF (data not presented).

Table 2 presents the distribution of background and study factors by SCOFF status and by dental fear. The SCOFF-positive students reported abnormal attitudes towards food, abnormal weight, and higher dental fear $(\mathrm{p}<0.001)$ more often than did SCOFF-negative students. Students who did not report a normal attitude

Table 1 Age, educational sector, dental fear, SCOFF status, BMI, mental well-being, attitude towards food and diagnosed eating disorders of the study population $(n=3090)$ by gender

\begin{tabular}{|c|c|c|c|c|}
\hline & $\begin{array}{l}\text { All } \\
\text { n (\%) }\end{array}$ & $\begin{array}{l}\text { Men } \\
\mathrm{n}(\%)\end{array}$ & $\begin{array}{l}\text { Women } \\
\mathrm{n}(\%)\end{array}$ & $p$ value ${ }^{\S}$ \\
\hline Age (2877) & & & & $<0.001$ \\
\hline $19-24$ & $1444(50.2)$ & $634(46.2)$ & $810(53.9)$ & \\
\hline $25-30$ & $1178(40.9)$ & $623(45.4)$ & $555(36.9)$ & \\
\hline $31-35$ & $255(8.9)$ & $116(8.4)$ & $139(9.2)$ & \\
\hline Educational sector (3077) & & & & 0.440 \\
\hline Univ & $1829(59.4)$ & $852(58.7)$ & $977(60.1)$ & \\
\hline UAS & $1248(40.6)$ & $599(41.3)$ & $649(39.9)$ & \\
\hline Dental fear (3013) & & & & $<0.001$ \\
\hline No or low dental fear & $2779(92.2)$ & $1352(96.2)$ & $1427(88.8)$ & \\
\hline High dental fear & $234(7.8)$ & $54(3.8)$ & $180(11.2)$ & \\
\hline sCOFF status* (3003) & & & & $<0.001$ \\
\hline Negative $(<2)$ & $2728(90.8)$ & $1372(96.4)$ & $1356(85.8)$ & \\
\hline Positive ( $\geq 2)$ & $275(9.2)$ & $51(3.6)$ & $224(14.2)$ & \\
\hline $\mathrm{BMI}^{\dagger}(3006)$ & & & & $<0.001$ \\
\hline$<18.5$ (underweight) & $61(2.0)$ & $16(1.1)$ & $45(2.8)$ & \\
\hline 18.5-24.9 (normal weight) & $2031(67.6)$ & $901(63.3)$ & $1130(71.4)$ & \\
\hline 25-29.9 (overweight) & $718(23.9)$ & $429(30.1)$ & $289(18.3)$ & \\
\hline$\geq 30$ (obese and extremely obese) & $196(6.5)$ & $77(5.4)$ & $119(7.5)$ & \\
\hline \multicolumn{5}{|l|}{ Mental well-being } \\
\hline Poor or moderate & $1060(34.6)$ & $495(34.2)$ & $564(35.0)$ & 0.634 \\
\hline Good or very good & $2000(65.4)$ & $952(65.8)$ & $1048(65.0)$ & \\
\hline Normal attitude towards food (3037) & & & & $<0.001$ \\
\hline Yes & $2451(80.7)$ & $1273(88.6)$ & $1178(73.6)$ & \\
\hline No/l don't know & $586(19.3)$ & $164(11.4)$ & $422(26.4)$ & \\
\hline \multicolumn{5}{|l|}{ Diagnosed eating disorders } \\
\hline Anorexia (2454) & $11(0.4)$ & $1(0.1)$ & $10(0.8)$ & 0.010 \\
\hline Bulimia (2426) & $14(0.6)$ & $2(0.2)$ & $12(1.0)$ & 0.010 \\
\hline Other (2415) & $27(1.1)$ & $3(0.3)$ & $24(1.9)$ & $<0.001$ \\
\hline
\end{tabular}

Univ Academic universities, UAS Universities of applied sciences

$\S$ Chi-square test

${ }^{\dagger}$ BMI: Body mass index was calculated from self-reported height and weight

*SCOFF (sick, control, one stone, fat, food) scores 2 or more out of five were considered positive 
Table 2 Age, gender, educational sector, dental fear, SCOFF status, BMI, mental well-being, attitude towards food of the study population $(n=3003)$ by SCOFF and by dental fear

\begin{tabular}{|c|c|c|c|c|c|c|}
\hline & \multicolumn{3}{|c|}{ SCOFF } & \multicolumn{3}{|c|}{ Dental fear } \\
\hline & $\begin{array}{l}\text { All } \\
\mathrm{n}\end{array}$ & $\begin{array}{l}\text { SCOFF positive } \\
\text { n (\%) }\end{array}$ & $p$-value $e^{\S}$ & $\begin{array}{l}\text { All } \\
\mathrm{n}\end{array}$ & $\begin{array}{l}\text { High } \\
\text { n (\%) }\end{array}$ & $p$-value $e^{\S}$ \\
\hline Age & 2882 & & & 2834 & & 0.097 \\
\hline $19-24$ & 1407 & $125(8.9)$ & & 1310 & $112(7.9)$ & \\
\hline $25-30$ & 1145 & $114(10.0)$ & & 1066 & $92(7.9)$ & \\
\hline $31-35$ & 250 & $16(6.4)$ & & 254 & $30(11.8)$ & \\
\hline Gender & 3003 & & $<0.001$ & 3013 & & $<0.001$ \\
\hline Men & 1423 & $51(3.6)$ & & 1406 & $54(3.8)$ & \\
\hline Women & 1580 & $224(14.2)$ & & 1607 & $180(11.2)$ & \\
\hline Educational sector & 3003 & & 0.033 & 3014 & & 0.003 \\
\hline Univ & 1775 & $146(8.2)$ & & 1807 & $119(6.6)$ & \\
\hline UAS & 1228 & $129(10.5)$ & & 1207 & $115(9.5)$ & \\
\hline Dental fear & 2943 & & $<0.001$ & - & - & \\
\hline No or low dental fear & 2715 & $229(8.4)$ & & - & - & \\
\hline High dental fear & 228 & $39(17.1)$ & & - & - & \\
\hline SCOFF status & - & - & & 2943 & & $<0.001$ \\
\hline Negative $(<2)$ & - & - & & 2675 & $189(7.0)$ & \\
\hline Positive ( $\geq 2$ ) & - & - & & 268 & $39(14.5)$ & \\
\hline $\mathrm{BMI}^{+}$ & 2955 & & $<0.001$ & 2945 & & $<0.001$ \\
\hline <18.5 (underweight) & 62 & $9(14.5)$ & & 62 & $6(9.7)$ & \\
\hline 18.5-24.9 (normal weight) & 1996 & $148(7.5)$ & & 1978 & $137(6.9)$ & \\
\hline 25-29.9 (overweight) & 705 & $77(10.9)$ & & 712 & $55(7.7)$ & \\
\hline$\geq 30$ (obese or extremely obese) & 192 & $36(18.8)$ & & 193 & $31(16.0)$ & \\
\hline Mental well-being & 2990 & & $<0.001$ & 2765 & & $<0.001$ \\
\hline Poor or moderate & 1035 & $165(15.9)$ & & 922 & $110(10.7)$ & \\
\hline Good or very good & 1935 & $109(5.6)$ & & 1843 & $122(6.2)$ & \\
\hline Normal attitude towards food & 2987 & & $<0.001$ & 2975 & & $<0.001$ \\
\hline Yes & 2412 & $64(2.6)$ & & 2399 & $157(6.5)$ & \\
\hline No/l don't know & 575 & $209(36.3)$ & & 576 & $75(13.0)$ & \\
\hline
\end{tabular}

Univ Academic universities, UAS Universities of applied sciences

$\S$ Chi-square test

*SCOFF (sick, control, one stone, fat, food) scores 2 or more out of five were considered positive

${ }^{+}$BMI: Body mass index was calculated from self-reported height and weight

towards food or were overweight/underweight also more frequently reported high dental fear $(\mathrm{p}<0.001)$. A positive SCOFF score was associated with high dental fear $(\mathrm{p}<0.001)$.

In the gender-specific logistic regression analyses, after controlling for age (Table 3), educational sector was associated significantly with high dental fear: female students from UAS experienced high dental fear more often than did their counterparts from academic universities $(\mathrm{p}<0.001)$. Adding SCOFF status and BMI to the model (Model 2) revealed that overweight males were more likely than others to report high dental fear $(\mathrm{OR}=2.4$; CI 1.3-4.4). SCOFF-positive female students experienced high dental fear more often than did other females $(\mathrm{OR}=1.6$; CI 1.0-2.4). (Adding SCOFF status and BMI in a stepwise approach yielded no change in outcome, data not shown).

Adding perceived mental well-being to the previous models (Model 3) showed that overweight among the males still significantly associated with high dental fear $(\mathrm{OR}=2.4$; CI 1.3-4.3) (Table 3). Mental wellbeing associated significantly with high dental fear in females; students who reported very poor to moderate mental well-being were more likely to report high dental fear than were those with good or very good mental well-being status $(\mathrm{p}<0.001)$, but SCOFF status was no longer significantly associated with dental fear. 
Table 3 Stepwise gender-specific results of logistic regression analyses $\left(n=3090^{*}\right)$, dental fear being the dependent variable (high fear $=1$ )

\begin{tabular}{|c|c|c|c|c|c|c|c|c|c|}
\hline & \multicolumn{3}{|c|}{ Model $1^{\mathrm{a}}$} & \multicolumn{3}{|c|}{ Model $2^{b}$} & \multicolumn{3}{|c|}{ Model $3^{c}$} \\
\hline & OR & $95 \% \mathrm{Cl}$ & $p$ & OR & $95 \% \mathrm{Cl}$ & $p$ & OR & $95 \% \mathrm{Cl}$ & $p$ \\
\hline \multicolumn{10}{|l|}{ Women } \\
\hline Educational sector & 1.8 & $1.3-2.4$ & $<0.001$ & 1.8 & $1.3-2.5$ & 0.001 & 1.8 & $1.3-2.5$ & $<0.001$ \\
\hline SCOFF & & & & 1.6 & $1.0-2.4$ & 0.043 & 1.3 & $0.8-2.0$ & 0.318 \\
\hline \multicolumn{10}{|l|}{$\mathrm{BMI}^{+}$} \\
\hline Underweight & & & & 0.9 & $0.3-2.4$ & 0.779 & 0.8 & $0.3-2.2$ & 0.653 \\
\hline Overweight & & & & 1.3 & $0.9-1.9$ & 0.137 & 1.2 & $0.8-2.0$ & 0.318 \\
\hline Mental well-being & & & & & & & 2.1 & $1.4-2.9$ & $<0.001$ \\
\hline \multicolumn{10}{|l|}{ Men } \\
\hline Educational sector & 1.1 & $0.6-2.0$ & 0.768 & 1.0 & $0.6-1.8$ & 0.969 & 1.0 & $0.6-1.8$ & 0.987 \\
\hline SCOFF & & & & 1.8 & $0.6-5.8$ & 0.305 & 1.6 & $0.5-5.3$ & 0.404 \\
\hline \multicolumn{10}{|l|}{$\mathrm{BMI}^{\dagger}$} \\
\hline Underweight & & & & 2.4 & $0.4-16.0$ & 0.368 & 2.4 & $0.4-16.2$ & 0.357 \\
\hline Overweight & & & & 2.4 & $1.3-4.4$ & 0.003 & 2.4 & $1.3-4.3$ & 0.004 \\
\hline Mental well-being & & & & & & & 1.7 & $0.9-3.0$ & 0.092 \\
\hline
\end{tabular}

Reference groups = academic university students, SCOFF negative (score < 2), normal weight (18.5-24.9) and good or very good mental well-being

OR odds ratio, 95\% Cl 95\% confidence interval, SCOFF Sick, control, one stone, fat, food

${ }^{\dagger}$ BMI: Body mass index (calculated from self-reported height and weight)

*Adjusted for underrepresentation of men

${ }^{\text {a }}$ Model 1 adjusted for age; ${ }^{b}$ Model 2 adds SCOFF status and BMl; ${ }^{\mathrm{c}}$ Model 3 adds mental well-being

\section{Discussion}

This comprehensive study endorsed our hypothesis that students with an abnormal BMI are more likely to experience high dental fear. Overweight was significantly associated with high dental fear among males, whereas educational sector and mental well-being were significant determinants of high dental fear among females. Female respondents and students of UAS reported high dental fear more often.

In this study, the prevalence of high dental fear was significantly lower among students with normal BMI. In the logistic regression analyses, after controlling for age, educational sector, SCOFF status and mental wellbeing, we observed that overweight or obese males $(\mathrm{BMI} \geq 25)$ were more likely than normal weight males to report high dental fear. There are only few studies investigating the association between dental fear and obesity, and the findings are inconsistent. One study found that obese females reported dental fear more often than others, while another research showed no significant difference between normal weight and overweight participants $[25,26]$. Our finding that overweight males were more likely to have high dental fear than normal weight males is in concordance with findings of a recent systematic review indicating that anxiety in general occurs more frequently in obese/ overweight people compared to normal weight persons [37].

We found an association between SCOFF status and dental fear, SCOFF-positive students reported high dental fear twice as often as SCOFF-negative students. Among females, when controlling for age, educational sector and BMI, those with positive SCOFF score were more likely to have high dental fear than those with negative SCOFF score, but this association was no longer significant after adding mental well-being to the model. Thus, the second part of our hypothesis was only partly true. Among males probably the low number of males with high dental fear and positive SCOFF-status $(n=54$, $\mathrm{n}=51$, respectively) was behind the non-significant association between dental fear and SCOFF-status. The high impact of mental health on dental fear may have attenuated the observed association in females. However, the association between SCOFF status and dental fear found in females in the model controlled for age, educational sector and BMI, can still be clinically important. Dentists may see the early signs of ED's and may have difficulties treating patients with high dental fear together other psychological problems (like EDs). Patients with high dental fear and EDs could benefit of team work of dentists and psychologists [38].

Although a few previous studies have reported high levels of anxiety among patients with EDs in dental 
settings [14], to the best of our knowledge, this is the first study to investigate the association between SCOFF status and dental fear. Our results show that about one in ten Finnish students scored positive on SCOFF. A recent systematic review and meta-analysis of 19 studies on student populations reported a $10.4 \%$ pooled prevalence of being at risk for EDs [39]. In studies limited to female participants only, the prevalence was as high as $38.2 \%$ [22]. The higher proportion of SCOFF-positive females in our study is in line with the current literature [13, 24].

Studies have well documented significant and positive correlation between SCOFF and other ED tests, and reported an association between SCOFF and BMI [22, 23]. In this study, only 39 students reported being diagnosed with EDs over the past 12 months, 53.8\% of whom scored positive in the SCOFF, however the Finnish version of SCOFF has been validated to have $78 \%$ sensitivity [33]. In this study we expected higher percentage of SCOFF positives among those with ED diagnosis. One reason for the observed low percentage might be attributed to the fact that some of the students had received appropriate treatments to their EDs and then recovered, and therefore scored negative in the SCOFF. In addition, the high number of missing responses regarding EDs might be due to skipping sensitive questions to hide ED history. Furthermore, atypical EDs are fairly common among university students [40] and this could have affected the association between SCOFF and ED diagnosis. In general, health care system's ability to identify EDs is limited and SCOFF can find symptoms of EDs not fulfilling the diagnostic criteria.

The connection between dental fear, BMI, EDs and problems of mental well-being may result from common vulnerability factors shared by psychological disorders [8]. For most people with dental fear, exogenous components, such as treatment or vicarious experiences [41], may be more important than psychopathology in the development of dental fear. However, among others, endogenous aetiology of dental fear may partially explain dental fear. The endogenous aetiology includes psychological vulnerability to anxiety disorders and other psychological problems [7, 8, 42]. Thus, the same students may have a constitutional vulnerability to developing, anxiety disorders (e.g. dental fear) and other problems of mental well-being (e.g. EDs) [6-8].

We collected the notably large data set used in the present study from an extensive national survey of the Finnish universities. To increase the students' participation, the questionnaires were sent as emails followed by five reminder invitations. On the web, responders can skip some questions as they are not in a face-toface interview, but studies report more missing values in paper-based surveys than in web-based ones [43]. Reports indicate that both designs have similar levels of selection bias [44]. The paper-based questionnaires can have slightly higher response rates, but web-based questionnaires are less expensive to administer, making them ideal for large-scale enquiries. The response rate of this study was in line with other web-based surveys [43-45]. Women participate in studies more often than men do and this was also the case in our study. In this study weighting adjustment (methodological approach previously proved successful $[2,3,9-11,31]$ ), was used to compensate for the underrepresentation of men. The participants of this study represented well the target population for age, study field, faculty and educational sector, when comparing with the national statistics 2015 published by the Education Statistics Finland [46]. Additionally, the health and health habit findings of the USHS 2016 are comparable to those of previous USHS studies [27], indicating no remarkable downward or upward trend, which also suggests that the composition of the participants has not changed considerably.

Single questions have been reported valid and reliable in measuring dental fear, when comparing to multi item questionnaires [29-31]. Even though clinical studies more often use multi-item questionnaires, single questions are easier and faster to answer for screening purposes. Adults are afraid of dental treatment and invasive stimuli have been reported as the most anxiety provoking [47]. In this study, we used a single question, which directly refer to 'dental care'; this question can be considered as a measure of dental fear [28]. Additionally, the question used in this study has given similar prevalence of dental fear as the questions referring to visiting a dentist [2, 3, 11]. Furthermore, enquiring dental fear out of a clinical setting, results in a more substantial estimation of and more comprehensive participation by the study population. This in turn reduces the risk for selection bias.

We calculated BMI using self-reported height and weight, which may be subject to subtle random errors. However, young university students are relatively aware of their body size and shape, and self-reported height and weight has been shown to be a reliable measure of BMI and predictor of obesity-associated health-risks [34-36]. This supports our belief that the data represents the accurate values. Because the survey focused university students, it did not include those who were not studying in academic universities or UAS. Thus, the results cannot be generalised to all young Finnish adults. In addition, due to the cross-sectional nature of the study, causal interpretation is not possible. 


\section{Conclusions}

Among Finnish university students BMI among males and problems of mental well-being among females were positively associated with high dental fear. The results of this study support possible common vulnerability factors that dental fear and other psychological disorders may share.

\section{Supplementary Information}

The online version contains supplementary material available at https://doi. org/10.1186/s12903-021-01449-8.

Additional file 1. USHS 2016 questions used in this study.

\section{Abbreviations}

ED: Eating disorder; BMI: Body mass index; SCOFF: Sick, control, one stone, fat, food; Univ: Academic universities; UAS: Universities of applied sciences; USHS: University Student Health Survey; FSHS: Finnish Student Health Service; AN: Anorexia nervosa; BN: Bulimia Nervosa; OR: Odds ratio; Cl: Confidence interval.

\section{Acknowledgements}

The authors thank all the students participating in this study and the Finnish Student Health Service for conducting the study and providing the data.

\section{Authors' contributions}

KK and VP participated in the planning of the USHS from the beginning. VP and JV designed this study and wrote the manuscript. MJS analysed and interpreted the data and wrote the manuscript. KK participated in the data collection and wrote the manuscript. All authors read and approved the final text.

\section{Funding}

No funding

\section{Availability of data and materials}

The data are available in the Finnish Social Science Data Archive where registered users can download data online according to the conditions set for this data. http://urn.fi/urn:nbn:fi:fsd:T-FSD3224

\section{Ethics approval and consent to participate}

The study was approved by the Ethics committee of the University of Turku (nr. 35/2015). Study permission was from the authorities of FSHS. The study was performed in accordance with the Declaration of Helsinki. Participation in the survey was voluntary and anonymous. Participating students gave their informed consent by voluntarily responding to the questionnaire.

\section{Consent for publication}

Not applicable.

\section{Competing interests}

The authors declare that they have no other competing interests. JIV is Associate Editor in BMC Oral Health.

\section{Author details}

${ }_{1}^{1}$ Medical Research Centre, Oulu University Hospital, Oulu, Finland. ${ }^{2}$ Department of Clinical Dentistry, University of Bergen, Bergen, Norway. ${ }^{3}$ Unit of Oral Health Sciences, University of Oulu, Oulu, Finland. ${ }^{4}$ Finnish Student Health Service, Helsinki, Finland. ${ }^{5}$ Institute of Dentistry, University of Turku, Turku, Finland.

Received: 19 March 2020 Accepted: 18 February 2021

Published online: 04 March 2021
References

1. Cianetti S, Lombardo G, Lupatelli E, Pagano S, Abraha I, Montedori A, et al. Dental fear/anxiety among children and adolescents. A systematic review. Eur J Paediatr Dent. 2017;18:121-30.

2. Lahti S, Vehkalahti MM, Nordblad A, Hausen H. Dental fear among population aged 30 years and older in Finland. Acta Odontolo Scand. 2007:65:97-102.

3. Liinavuori A, Tolvanen M, Pohjola V, Lahti S. Changes in dental fear among Finnish adults: a national survey. Community Dent Oral Epidemiol. 2016:44:128-34.

4. Luoto A, Tolvanen M, Pohjola V, Rantavuori K, Karlsson L, Lahti S. A longitudinal study of changes and associations in dental fear in parent/ adolescent dyads. Int J Paediatr Dent. 2017;27:506-13.

5. American Psychiatric Association. Diagnostic and Statistical Manual of Mental Disorders. 5th ed. Washington: American Psychiatric Association; 2013

6. Lähteenmäki S, Saarni S, Suokas J, Saarni S, Perälä J, Lönnqvist J, et al. Prevalence and correlates of eating disorders among young adults in Finland. Nord J Psychiatry. 2014;68:196-203.

7. Locker D, Poulton R, Thomson WM. Psychological disorders and dental anxiety in a young adult population. Community Dent Oral Epidemiol. 2001;29:456-63.

8. Riskind JH, Alloy L. Cognitive vulnerability to psychological disorders: overview of theory, design and methods. J Soc Clin Psychol. 2006:25:705-25.

9. Pohjola V, Mattila AK, Joukamaa M, Lahti S. Anxiety and depressive disorders and dental fear among adults in Finland. Eur J Oral Sci. 2011;119:55-60.

10. Pohjola V, Mattila AK, Joukamaa M, Lahti S. Alcohol use disorder, smoking and dental fear among adults in Finland. Acta Odontol Scand. 2013;71:300-6.

11. Pohjola V, Rekola A, Kunttu K, Virtanen Jl. Association between dental fear and oral health habits and treatment need among University students in Finland: a national study. BMC Oral Health. 2016;27:16-26.

12. Jahrami $H$, Saif $Z$, Faris MA, Levine MP. The relationship between risk of eating disorders, age, gender and body mass index in medical students: a meta-regression. Eat Weight Disord. 2019;24:169-77.

13. McBride O, McManus S, Thompson J, Palmer RL, Brugha T. Profiling disordered eating patterns and body mass index (BMI) in the English general population. Soc Psychiatry Psychiatr Epidemiol. 2013;48:783-93.

14. Sirin Y, Yucel B, Firat D, Husseinova-Sen S. Assessment of dental fear and anxiety levels in eating disorder patients undergoing minor oral surgery. J Oral Maxillofac Surg. 2011;69:2078-85.

15. Willumsen T, Graugaard PK. Dental fear, regularity of dental attendance and subjective evaluation of dental erosion in women with eating disorders. Eur J Oral Sci. 2005:113:297-302.

16. Dynesen AW, Gehrt CA, Klinker SE, Christensen LB. Eating disorders: experiences of and attitudes toward oral health and oral health behavior. Eur J Oral Sci. 2018;126:500-6.

17. Hautala LA, Junnila J, Helenius H, Väänänen AM, Liuksila PR, Räihä H, et al. Towards understanding gender differences in disordered eating among adolescents. J Clin Nurs. 2008;17:1803-13.

18. Keski-Rahkonen A, Hoek HW, Linna MS, Raevuori A, Sihvola E, Bulik CM, et al. Incidence and outcomes of bulimia nervosa: a nationwide population-based study. Psychol Med. 2009;39:823-31.

19. Nelson MC, Story M, Larson NI, Neumark-Sztainer D, Lytle LA. Emerging adulthood and college-aged youth: an overlooked age for weight-related behavior change. Obesity (Silver Spring). 2008;16:2205-11.

20. Deliens T, Clarys P, De Bourdeaudhuij I, Deforche B. Determinants of eating behaviour in university students: a qualitative study using focus group discussions. BMC Public Health. 2014;18:14-53.

21. Morgan JF, Reid F, Lacey JH. The SCOFF questionnaire: assessment of a new screening tool for eating disorders. BMJ. 1999;319:1467-8.

22. Saleh RN, Salameh RA, Yhya HH, Sweileh WM. Disordered eating attitudes in female students of An-Najah National University: a cross-sectional study. J Eat Disord. 2018. https://doi.org/10.1186/s40337-018-0204-4.

23. Ko N, Tam DM, Viet NK, Scheib P, Wirsching M, Zeeck A. Disordered eating behaviors in university students in Hanoi. Vietnam J Eat Disord. 2015. https://doi.org/10.1186/s40337-015-0054-2. 
24. Tavolacci MP, Grigioni S, Richard L, Meyrignac G, Déchelotte P, Ladner J. Eating disorders and associated health risks among university students. J Nutr Educ Behav. 2015;47:412-20.

25. Forslund HB, Lindroos AK, Blomkvist K, Hakeberg M, Berggren U, Jontell $M$, et al. Number of teeth, body mass index, and dental anxiety in middleaged Swedish women. Acta Odontol Scand. 2002;60:346-52.

26. Dumitrescu AL, Kawamura M. Involvement of psychosocial factors in the association of obesity with periodontitis. J Oral Sci. 2010;52:115-24.

27. Kunttu K, Pesonen T, Saari J. Student Health Survey 2016: A national survey among Finnish university students. Research publications of the Finnish Student Health Service, 2017. 48. https://www.yths.fi/app/uploa ds/2020/03/KOTT_2016_ENG.pdf. Accessed 20 Jan 2021.

28. Manderbacka K. Questions on survey questions on health. Helsinki: Akademitryck AB. Swedish Institute for Social Research; 1998.

29. Neverlien PO. Assessment of a single-item dental anxiety question. Acta Odontol Scand. 1990;48:365-9.

30. Viinikangas A, Lahti S, Yuan S, Pietilä I, Freeman R, Humphris G. Evaluating a single dental anxiety question in Finnish adults. Acta Odontol Scand. 2007;65:236-40.

31. Pohjola VP, Puolakka A, Kunttu K, Virtanen Jl. Association between dental fear, physical activity and physical and mental well-being among Finnish university students. Acta Odontol Scand. 2020;78:45-51.

32. Kutz AM, Marsh AG, Gunderson CG, Maguen S, Masheb RM. Eating disorder screening: a systematic review and meta-analysis of diagnostic test characteristics of the SCOFF. J Gen Intern Med. 2020:35:885-93.

33. Lähteenmäki S, Aalto-Setälä T, Suokas JT, Saarni SE, Perälä J, Saarni S. Validation of the Finnish version of the SCOFF questionnaire among young adults aged 20 to 35 years. BMC Psychiatry. 2009. https://doi. org/10.1186/1471-244X-9-5

34. Virtanen Jl, Muikku T, Similä T, Cinar AB, Pohjola V. Physical activity, BM and oral health behaviour among adolescents: Finnish School Health Promotion Study. Eur J Public Health. 2019;29:296-302.

35. Ng M, Fleming T, Robinson M, Thomson B, Graetz N, Margono C, et al. Global, regional and national prevalence of overweight and obesity in children and adults during 1980-2013: a systematic analysis for the Global Burden of Disease Study 2013. Lancet. 2014;384:766-81.

36. Korpela K, Roos E, Lallukka T, Rahkonen O, Lahelma E, Laaksonen M. Different measures of body weight as predictors of sickness absence. Scand J Public Health. 2013;41:25-31.
37. Amiri S, Behnezhad S. Obesity and anxiety symptoms: a systematic review and meta-analysis. Neuropsychiatry. 2019;33:72-89.

38. De Jongh A, Adair P, Meijerink-Anderson M. Clinical management of dental anxiety: what works for whom? Int Dent J. 2005;55:73-80.

39. Jahrami $H$, Sater $M$, Abdulla A, Faris MA, AlAnsari A. Eating disorders risk among medical students: a global systematic review and meta-analysis Eat Weight Disord. 2019;24:397-410.

40. Castelao-Naval O, Blanco-Fernández A, Meseguer-Barros CM, ThuissardVasallo IJ, Cerdá B, Larrosa M. Life style and risk of atypical eating disorders in university students: reality versus perception. Enferm Clin. 2019:29:280-90.

41. Rachman S. Neo-conditioning and the classical theory of fear acquisition. Clin Psychol Rev. 1991;11:155-73.

42. Armfield JM. Cognitive vulnerability: a model of the etiology of fear. Clin Psychol Rev. 2006;26:746-68.

43. Ebert JF, Huibers L, Christensen B, Christensen MB. Paper- or Web-Based questionnaire invitations as a method for data collection: cross-sectional comparative study of differences in response rate, completeness of data and financial cost. J Med Internet Res. 2018. https://doi.org/10.2196/ jmir.8353.

44. Shih TH, Fan X. Comparing response rates from web and mail surveys: a meta-analysis. Fields Methods. 2008;20:249-71.

45. Groves RM. Nonresponse rates and nonresponse bias in household surveys. Public Opinion Quarterly. 2006;70:646-75.

46. Vipunen. Education Statistics Finland. Ministry of Education and Culture. https://vipunen.fi/en-gb/ Accessed 20 Jan 2021.

47. Oosterink FM, de Jongh A, Aartman IHA. What are people afraid of during dental treatment? Anxiety-provoking capacity of 67 stimuli characteristic of the dental setting. Eur J Oral Sci. 2008;116:44-51.

\section{Publisher's Note}

Springer Nature remains neutral with regard to jurisdictional claims in published maps and institutional affiliations.
Ready to submit your research? Choose BMC and benefit from:

- fast, convenient online submission

- thorough peer review by experienced researchers in your field

- rapid publication on acceptance

- support for research data, including large and complex data types

- gold Open Access which fosters wider collaboration and increased citations

- maximum visibility for your research: over $100 \mathrm{M}$ website views per year

At $\mathrm{BMC}$, research is always in progress.

Learn more biomedcentral.com/submissions 